\title{
Um acordo insólito: ensino religioso sem ônus para os poderes públicos na primeira LDB
}

\author{
Luiz Antônio Cunha \\ Vânia Fernandes \\ Universidade Federal do Rio de Janeiro
}

\begin{abstract}
Resumo
Este artigo aborda o ensino religioso nas escolas públicas, buscando identificar os posicionamentos de grupos políticoideológicos em torno da questão durante a tramitação do projeto da Lei de Diretrizes e Bases da Educação Nacional promulgada em 20 de dezembro de 1961. A análise tomou como fonte o Diário do Congresso Nacional no período entre 1948 e 1962. Constatou-se que, durante o longo período de tramitação do projeto na Câmara dos Deputados, diferentes pressões imprimiram suas marcas na LDB: de um lado, a extensão do dispositivo constitucional sobre o ensino religioso nas escolas públicas, a fim de atender aos interesses da Igreja Católica, a única organização manifestamente comprometida com sua oferta; de outro lado, uma aliança de amplo espectro, mas inorgânica, que, sem condições políticas de defender um projeto laico para a educação pública, limitou-se a resistir ao avanço do confessionalismo. Ao fim e ao cabo, nenhum dos dois lados foi capaz de fazer valer completamente suas demandas, de modo que a lei promulgada e sancionada resultou em um produto híbrido, em razão de possível acordo entre os membros da Comissão de Educação e Cultura da Câmara dos Deputados, pelo menos no que diz respeito à questão do ensino religioso nas escolas públicas.
\end{abstract}

\section{Palavras-chave}

LDB - Educação brasileira - Política educacional - Ensino religioso - Laicidade.

\section{Contato:}

Luiz Antônio Cunha

lacunha90@gmail.com 


\title{
A curious agreement: religious education without cost for the public authorities in the first $L D B$
}

Luiz Antônio Cunha

Vânia Fernandes

Universidade Federal do Rio de Janeiro

\begin{abstract}
This article deals with religious education in public schools, trying to identify the position of political-ideological groups around this issue during the process of approval of the proposal for a Law of Directives and Bases for National Education (Lei de Diretrizes e Bases da Educação Nacional - LDB), which was promulgated on 20 December 1961. The analysis took as its source the Diário do Congresso Nacional (Annals of the National Congress) in the period between 1948 and 1962. It was observed that during the long course of the proposal inside the House of Representatives, various pressures left their marks on the LDB: on the one hand, the length of the constitutional regulation about religious education in public schools, so as to meet the interests of the Catholic Church, the single organization openly committed to its offer; on the other hand, a wide ranging, albeit unsystematic, alliance which, lacking the political strength to defend a lay project for public education, was limited to try and resist the surge of confessionalism. Eventually, none of the sides was able to implement their demands in full, so that the law promulgated and sanctioned resulted in a hybrid product, possibly as a consequence of agreements among the members of the Committee of Education and Culture of the House of Representatives, at least with respect to the issue of religious education in public schools.
\end{abstract}

\section{Keywords}

LDB - Brazilian education - Educational policy - Religious education - Laity.

Contact:

Luiz Antônio Cunha

lacunha90@gmail.com 
A primeira Lei de Diretrizes e Bases da Educação Nacional (Lei $\mathrm{n}^{\circ}$ 4.024), promulgada em 20 de dezembro de 1961, é derivada do processo mais estudado dentre todos os que adquiriram relevo no campo educacional do país ${ }^{1}$. Com efeito, em nenhum outro momento de nossa história a educação esteve em tamanha evidência, mobilizando forças políticas tão diversas e suscitando debates tão intensos quanto no período entre 1948 e 1961.

Mudança política de grande repercussão marcou o início dos treze anos de tramitação do projeto, efetivada na recomposição política do governo do presidente Eurico Gaspar Dutra. Mantida a posição hegemônica do Partido Social Democrático (PSD) dirigido pelos remanescentes do Estado Novo, a resultante da correlação de forças deslocou-se para a direita, substituído que foi o Partido Trabalhista Brasileiro (PTB) pela União Democrática Nacional (UDN) na coalizão partidária de sustentação parlamentar e de composição ministerial. 0 fim do período de gestação da LDB foi marcado pela introdução do regime parlamentarista que restringiu os poderes do presidente João Goulart, recomposição política que, uma vez mais, destinava-se a conter o mesmo PTB e seus aliados à esquerda.

A Igreja Católica ocupou o proscênio da política, posição confirmada, a posteriori, pelas marchas da família com Deus, pela liberdade, imediatamente antes e depois do golpe militar de março/abril de 1964. Não é exagero, pois, dizer que as lutas em torno da LDB foram travadas no bojo do processo político-ideológico cujo desfecho foi o golpe de Estado.

A dimensão religiosa do processo de gestação da LDB foi destacada por vários auto-

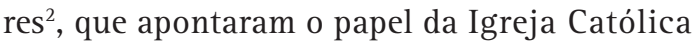
na legitimação dos interesses particularistas, não apenas dos seus próprios, mas de todo o setor privado, que ainda não tinha força suficiente para dispensar a legitimidade que

1 - Ver, por exemplo, Barros (1960), Buffa (1979), Fernandes (1966), Lima (1978), Montalvão (2011), Moreira (1960), Romanelli (1978), Saviani (2005 e 2007) e Villalobos (1969).

2- Em especial, Barros (1960), Buffa (1979), Fernandes (1966), Lima (1978), Moreira (1960) e Villalobos (1969). aquela instituição lhe propiciava. Porém, um aspecto não foi analisado por nenhum dos estudos examinados: a inserção, no projeto de LDB, durante sua tramitação na Câmara dos Deputados, de uma limitação ao ensino religioso nas escolas públicas, o qual deveria ser realizado sem ônus para os poderes públicos. Causa perplexidade que a vitória do privatismo, particularmente de seu mais importante protagonista - a Igreja Católica, instituição a quem interessava diretamente o ensino religioso nas escolas públicas -, tivesse aceitado tal restrição. Afinal, os subsídios públicos ao ensino privado foram a pedra de toque dos conflitos, pelo menos nos últimos anos de tramitação do projeto de lei.

É justamente aquela limitação que este artigo almeja compreender. Para isso, foi analisada a tramitação do projeto de LDB na Câmara dos Deputados, reexaminando-se o Diário do Congresso Nacional (DCN) à luz da conjuntura política e dos debates educacionais, em busca de elementos que poderiam ter escapado aos que pesquisaram previamente o tema. Em suma, partimos de elementos conhecidos, relativos ao contexto político, e concluímos com uma hipótese sobre a inserção, no projeto de lei, da cláusula de restrição no uso de recursos públicos para o ensino religioso nas escolas oficiais.

\section{Tramitação tormentosa do projeto de LDB}

Foge ao objetivo deste texto o exame da discussão sobre o ensino religioso nas escolas públicas na Assembleia Constituinte de 1946. Para os interessados nessa questão, remetemos ao trabalho de Romualdo Portela de Oliveira (1990), que analisa detalhadamente as emendas apresentadas e os argumentos oferecidos pelas diferentes correntes político-ideológicas. Limitamo-nos a mencionar que comunistas como Luís Carlos Prestes, socialistas como Hermes Lima e liberais como Aliomar Baleeiro apresentaram emendas que pretendiam retomar o caráter laico do ensino público ou, então, limitar o ensino religioso nas escolas públicas, 
de modo que ele fosse ofertado apenas fora do horário das aulas, ministrado somente por pessoas estranhas ao corpo docente dos estabelecimentos de ensino e sem ônus para os poderes públicos. Essas emendas foram todas rejeitadas, prevalecendo na Constituição o texto proposto pela Liga Eleitoral Católica (LEC) que dizia:

0 ensino religioso constitui disciplina dos horários das escolas oficiais, é de matrícula facultativa e será ministrado de acordo com a confissão religiosa do aluno, manifestada por ele, se for capaz, ou pelo seu representante legal ou responsável. (BRASIL, 1946)

Esse artigo da Constituição foi o ponto de partida do projeto da Lei de Diretrizes e Bases da Educação Nacional.

A translação do Governo Dutra para a direita do espectro político, em 1947, abriu caminho para que quadros da UDN assumissem vários ministérios, inclusive o da educação. No mesmo movimento, os parlamentares comunistas tiveram seus mandatos cassados e postos na clandestinidade, o que lhes impediu de repetir, na gestação da LDB, o protagonismo da Constituinte, especialmente a aliança com os liberais. Foi nesse contexto que o udenista baiano Clemente Mariani assumiu o Ministério da Educação e convocou outros liberais (inclusive seu conterrâneo Anísio Teixeira) para a produção do que tinha sido o maior projeto desse grupo, desde o Manifesto de 1932: uma Lei de Diretrizes e Bases da Educação Nacional.

0 projeto de LDB já saiu do Ministério da Educação, em 1948, com o feitio adequado às demandas principais da Igreja Católica, pelo menos no que dizia respeito ao ensino religioso nas escolas públicas, tal como veremos no próximo item. Isso, todavia, não ocorreu em todas as questões, como no caso crucial do status dos estabelecimentos privados de educação.

Nessa altura, a Associação de Educação Católica do Rio de Janeiro (AEC) já havia iniciado articulações para representar os interesses da Igreja Católica e dos estabecimentos de ensino privado na elaboração da LDB. Em 1948 , antes que o projeto fosse divulgado, mas com suas linhas gerais já definidas, realizou-se em São Paulo o III Congresso Nacional de Estabelecimentos Particulares de Ensino, no qual a hegemonia dos católicos foi assegurada. Sendo estabelecimentos privados, as escolas católicas tinham, decerto, interesses em receber subsídios governamentais que o anteprojeto supostamente obstava (ou não era suficientemente pródigo), embora essa não fosse sua motivação principal, como o era para as escolas não confessionais, que subordinavam os alvos doutrinários aos pecuniários (LIMA, 1978). Como convinha aos empresários do ensino dissimular esses interesses sob o manto de valores abstratos, principalmente os defendidos por uma instituição dotada da legitimidade da Igreja Católica, aceitaram a liderança da AEC na luta contra o suposto monopólio do ensino pelo Estado. Na realidade, por meio do argumento da liberdade de ensino, o que essa instituição buscava era:

Assegurar às empresas particulares de ensino condições econômicas pela possibilidade de subvenções substanciais, sem as quais elas não poderiam sobreviver, em virtude do crescente empobrecimento da classe média e da nascente preferência do proletariado urbano pelo ensino técnico. (MOREIRA, 1960, p. 289)

Quando a Associação Brasileira de Educação (ABE) realizou a X Conferência Nacional de Educação no Rio de Janeiro, em novembro de 1950, tendo como tema central o projeto de LDB, os defensores da liberdade de ensino já estavam bem organizados em todo o país. Mas, nessa conjuntura, os educadores liberais tinham outros adversários: os defensores do centralismo da política educacional estadonovista. Foi visando à atuação destes na Câmara, capitaneados pelo deputado Gustavo Capanema (PSD-MG), ex-ministro da educação do Governo Vargas, que os liberais elaboraram um anteprojeto alternativo de LDB, que tentava eliminar as resistências dos 
centralizadores. A sugestão da $\mathrm{ABE}$ foi enviada ao Congresso Nacional e juntada, para estudos, ao projeto original (CUNHA, 1981).

Ao contrário do que aconteceu na década de 1930, a ABE já não era um fórum que reunia parcela significativa dos educadores brasileiros. A X Conferência não teve grande participação e as conclusões do evento foram resultado das reflexões de apenas alguns educadores, dentre os quais dirigentes de órgãos do aparelho escolar estatal. Era como se, para contornar resistências de Capanema e de seus liderados no Congresso Nacional, os dirigentes do aparelho escolar utilizassem a $\mathrm{ABE}$, entidade da sociedade civil, para influenciar o legislativo.

Esse artifício continuou a ser empregado na segunda metade da década de 1950 , quando o conflito se tornou mais intenso, com ataques de defensores da liberdade de ensino aos dirigentes educacionais defensores da escola pública. Foi o padre-deputado Fonseca e Silva (PSD-GO) quem desencadeou esses ataques, em 1956, ao pronunciar discurso na Câmara. Anísio Teixeira, então diretor do Instituto Nacional de Estudos Pedagógicos (INEP), esteve na mira principal do sacerdote, que o acusou de articular-se contra o patrimônio moral e espiritual da Igreja Católica, no setor do ensino, e de associar-se a uma campanha camuflada dos comunistas. 0 educador baiano defendeu-se das acusações, argumentando que

hostilizar qualquer crença religiosa seria para ele, ato profundamente antidemocrático, da mesma forma que, no exercício da função pública, tentar o benefício discriminativo de uma religião particular. (VILLALOBOS, 1969, p. 72)

Esse movimento de ataque ao maior dos educadores brasileiros gerou várias reações, inclusive da $\mathrm{ABE}$, que se posicionou e funcionou como instituição de desagravo e apoio aos outros associados visados, como Fernando de Azevedo e Almeida Junior.

Na Câmara dos Deputados, depois de atacado pelos parlamentares oriundos do Estado
Novo (Gustavo Capanema à frente), pelo seu viés descentralizador, supostamente ameaçador à unidade nacional, o projeto de LDB foi esquecido e extraviado. Em 1951, a Câmara determinou a recomposição do projeto, o que só aconteceu seis anos mais tarde. A partir de então, a tramitação foi retomada e a AEC reposicionou-se para defender os interesses privados. Atenta às discussões na Câmara, a entidade apoiou prontamente 0 segundo substitutivo do deputado Carlos Lacerda (UDN-GB), apresentado em 1959, que reforçava os interesses do privatismo ao reivindicar do Poder Público "todas as regalias e proteção para a iniciativa privada em detrimento da escola pública” (ROMANELLI, 1978, p. 175). Além disso, propunha a presença obrigatória de representantes das instituições educacionais nos órgãos de deliberação coletiva dos sistemas de ensino. 0 substitutivo foi comemorado pela entidade, uma vez que o documento se inspirou nas conclusões do III Congresso de Estabelecimentos Particulares de Ensino (1948). Na defesa de seus interesses, esse grupo promoveu uma intensa campanha em favor da liberdade de ensino contra a suposta pretensão de monopólio da educação pelo Estado, apesar do disposto no artigo 167 do projeto de LDB, que dizia: "o ensino dos diferentes ramos será ministrados pelos poderes públicos e é livre à iniciativa privada”. Todavia, essa bandeira abriu caminho para a introdução de diversos argumentos em defesa dos subsídios à escola privada e da minimização da presença do Estado no campo educacional, explicitados nas proposições apresentadas durante a tramitação do projeto.

A primeira reação coletiva contra o substitutivo de Lacerda foi expressa pelo Manifesto dos Educadores, redigido por Fernando de Azevedo e publicado pela primeira vez em São Paulo, em $1^{\circ}$ de julho de 1959 . Nele se diz que os educadores signatários do manifesto dos "pioneiros da educação nova”, de 1932, "mais uma vez convocados", vinham defender os princípios gerais daquele documento, considerados ainda válidos um quarto de século depois. Os educadores defendiam a expansão do ensino público como condição necessária à 
democracia, à igualdade de oportunidades e ao desenvolvimento econômico baseado na industrialização. Foi assinado por pioneiros, como Anísio Teixeira, Almeida Junior, Hermes Lima, Paschoal Lemme e Cecília Meireles. A eles se juntaram intelectuais de vanguarda, como Caio Prado Junior, Sérgio Buarque de Holanda, Florestan Fernandes, Antônio Cândido e Álvaro Vieira Pinto; militares, como o coronel Nelson Werneck Sodré, o marechal Mário Travassos e o almirante Octacílio Cunha; jovens professores e pesquisadores universitários, como César Lates, José Arthur Giannotti, Darcy Ribeiro, Fernando Henrique Cardoso, Maria Isaura Pereira de Queiroz, Celso Beisiegel e Douglas Monteiro; e artistas, como Augusto Rodrigues.

Para os signatários do manifesto, a campanha contra a escola pública era

praticamente uma larga ofensiva para obter mais recursos do Estado, do qual se reclama, não aumentar cada vez mais os meios de que necessita o ensino público, mas dessangrá-lo para sustentar, com o esgotamento das escolas que mantém, as de iniciativa privada. (MAIS, 1959, p. 10)

0 documento advertiu, ainda, para os efeitos nefastos dessa campanha sobre "os combalidos recursos financeiros do país”3 (p. 15).

É possível que esse manifesto tenha iniciado a Campanha de Defesa da Escola Pública, um grande movimento de mobilização, predominantemente paulista, com o apoio aberto e intenso do jornal O Estado de São Paulo. Cumpre lembrar que Fernando de Azevedo, relator daquele documento, começou sua carreira educacional como redator desse diário.

Acirravam-se, assim, os conflitos que opunham os defensores da escola pública aos paladinos da liberdade de ensino, para quem a religião católica foi sempre empregada como elemento legitimador, mesmo quando não se

3 - Para uma análise desse documento, para além dos objetivos deste artigo, ver Sanfelice (2007) tratava especificamente do ensino religioso no currículo das escolas públicas.

A despeito da polarização que se armava, uma visão menos envolvida com os conflitos daquela conjuntura permite ver um quadro mais complexo da situação. Foi o que mostrou Sérgio de Sousa Montalvão (2011), ao sublinhar as proximidades entre os projetos substitutivos de Carlos Lacerda e os educadores afinados com Anísio Teixeira, como Almeida Junior. 0 deputado carioca produziu um discurso que mostrava a convergência de seus propósitos com a renovação pretendida pelos liberais, ao condenar, como aqueles, o centralismo da política educacional do Estado Novo. E foi além, ao identificar o dualismo educacional com a ditadura varguista, que teria pretendido dividir os brasileiros entre trabalhadores manuais e intelectuais, entre os que teriam a vocação técnica e os vocacionados para a cultura. Assim, ao criticar a concepção educacional qualificada por ele como aristocrática, oligárquica, reacionária e totalitária da cultura e da escola, o deputado carioca abriu uma conexão com liberais e até com setores políticos situados mais à esquerda.

Embora Lacerda embaralhasse os termos do debate (centralismo burocrático = monopólio estatal), seus oponentes tinham dificuldade para mostrar ao grande público, e até mesmo aos parlamentares, a congruência entre a ênfase nas redes públicas de ensino e a descentralização da administração escolar, conforme mostrou Montalvão (2011). Essa dificuldade era tão grande quanto a de distinguir a defesa de uma posição laica sobre política educacional de uma suposta tática comunista (= ateia) de combate à religião da maioria da população.

No mesmo ano em que Lacerda expressava, em seu projeto substitutivo de 1959, os interesses dos setores mais conservadores da Igreja Católica e dos empresários do ensino, começava em Roma o Concílio Vaticano II, que trouxe forte renovação ao pensamento católico no Brasil. Parte do clero e dos intelectuais leigos passou a interpretar o Evangelho e até mesmo os documentos pontifícios à luz das 
realidades sociais. Alceu Amoroso Lima, devoto protagonista do projeto educacional autoritário da era de Vargas, foi o expoente máximo dessa inflexão. Num artigo sobre a questão educacional, dizia ele que o papel do Estado não podia ser apenas supletivo, de acordo com os princípios extraídos da natureza original das coisas, como advogavam os defensores da escola privada; deveria ser um papel ativo, conforme a realidade social (LIMA, 1959).

Durante os anos de 1960 e 1961, alguns setores da Ação Católica passaram a defender as posições da Campanha Nacional de Defesa da Escola Pública. Porém, foi só depois de promulgada e sancionada a LDB que surgiram depoimentos como o seguinte:

Defender abstratamente os direitos da família significa, de fato, favorecer as famílias economicamente privilegiadas, isto é, a sua ruína, porque o que se inclui no sentido de seus privilégios arruína sua promoção humana. (Frei Thomas Cardonnel apud SOUZA, 1962, p. 23)

Até então, os militantes da Ação Católica, principalmente os da Juventude Universitária Católica (JUC), de onde saíram dirigentes da UNE a partir de meados de 1961, defendiam posições isoladas favoráveis à escola pública. Mesmo quando equipes de base assumiam essa posição, os documentos do movimento eram dúbios, trazendo, quando muito, críticas suaves à seletividade social das escolas privadas, o que se explicava pela necessidade de conciliação das exigências práticas e ideológicas do novo engajamento com as orientações oficiais da hierarquia eclesiástica.

Três meses depois de empossado na Presidência da República, em setembro de 1961, João Goulart sancionou a LDB, sem que os termos dos compromissos políticos propiciadores do novo regime parlamentarista lhe permitissem utilizar o poder de vetar as leis promulgadas pelo Congresso, pelo menos na extensão pretendida pelas forças políticas que defenderam sua posse.

\section{Laicidade apesar da Constituição}

A determinação da Constituição de 1946 no que se refere à inserção da disciplina ensino religioso nos horários das escolas públicas deve ter funcionado como elemento para atenuar o conflito confessionalismo versus laicidade. Mesmo com o forte envolvimento do clero católico na defesa da liberdade de ensino, a defesa da laicidade nas escolas públicas permaneceu relegada a posição secundária no debate político. Houve, todavia, algumas manifestações pró ensino laico, em caráter aberto ou fechado, que mencionaremos a seguir.

0 primeiro posicionamento partiu dos professores paulistas de nível médio e superior. Em 1957, foi realizado o IV Congresso dos Antigos Alunos da Faculdade de Filosofia, Ciências e Letras da Universidade de São Paulo, que reprovou os subsídios públicos às escolas privadas e o ensino religioso nas escolas of ciais, e apoiou os educadores defensores do ensino público, particularmente os que eram alvo de calúnias. Depois de dez consideranda, assim concluiu e propôs a tese aprovada:

I - Que o IV Congresso dos Antigos Alunos e a Diretoria a ser eleita, por todas as considerações apresentadas, e fiéis às tradições culturais e democráticas da Faculdade de Filosofia, Ciências e Letras, da USP, se manifestem contrários ao ensino religioso nas escolas públicas;

II - Que se manifestem contra a subvenção, pelo Estado, das escolas religiosas, a não ser as que se dediquem realmente ao ensino gratuito de alunos pobres, sem qualquer discriminação religiosa;

III - Que o IV Congresso dos Antigos Alunos aprove uma moção de desagravo aos ilustres educadores Fernando de Azevedo, A. Almeida Junior e Anísio Teixeira, que por ocasião do I Congresso Estadual de Educação, foram injuriados por um setor mal informado e sectário da imprensa de Ribeirão Preto. (CONTRA, 1957, p. 24) 
Anísio Teixeira também se manifestou sobre a laicidade no ensino público, mas em carta pessoal. Vítima da campanha privatista-clerical, que o taxava de marxista, ateu e estatista, ele preferiu manter o perfil baixo e expor suas posições em carta dirigida ao célebre jornalista católico conservador Gustavo Corção ${ }^{4}$. Nessa carta, o presidente do Intituto Nacional de Estudos Pedagógicos (INEP) criticou, genericamente, quatro artigos publicados por aquele em $O$ Estado de São Paulo, em janeiro e fevereiro de 1958.

Em A liberdade de ensino, Corção defendeu a tese de que a origem dos desatinos estava na centralização do ensino, que ele fazia sinônimo de estatização. Em reação, ele convocou os católicos para lutarem contra o monopólio do ensino pelo Estado e a não aceitarem compensações insuficientes:

pode ser que muitos católicos tenham ficado contentíssimos com o prato de lentilhas, o famoso ensino religioso nas escolas, com que se negociou a humana dignidade. (CORÇÃO, 1958a, p. 88)

Em A quem compete educar?, publicado na semana seguinte, o jornalista prosseguiu na crítica aos seus confrades. Começou por evocar a encíclica de Pio XI, Divini illius Magistri, que dizia terem a família e a Igreja primazia sobre o Estado na educação. Perguntou-se por que os católicos brasileiros omitiam-se diante da reivindicação dessa diretriz na política educacional. Somente lhe ocorreu a hipótese de que eles tivessem se contentado com a obrigatoriedade do latim nas escolas secundárias e do ensino religioso nas escolas públicas. Ou, então, por inexperiência política. Advertia para o fato de que esse privilégio poderia ser retirado, como Perón havia feito na Argentina. Ele teria começado por apoiar o ensino religioso nas escolas of1ciais. "Protegeu-o até cansar-se, e então passou a perseguir. A história é monótona” (CORÇÃO,

4 - Na conjuntura conciliar, Gustavo Corção foi o contraponto direitista da translação para a esquerda de Alceu Amoroso Lima. 1958b, p. 4). No terceiro artigo da série, Uma afronta pessoal, publicado na semana seguinte, o jornalista repudiou a obrigatoriedade curricular do Ministério da Educação, que retirou dos pais e dos diretores de colégios o direito de escolher a educação a ministrar aos filhos/alunos. Sua ojeriza pelo currículo prefixado era tal que, segundo Corção, até mesmo o latim deveria ser facultativo, apesar de ele considerar seu estudo essencial para a formação intelectual e humanista dos jovens (CORÇÃO, 1958c). Essa posição foi retomada no artigo Ainda a liberdade de ensino, publicado em 16 de fevereiro de 1958 no mesmo jornal. Sua argumentação foi refinada com a afırmação a seguir:

Meu ideal não é a da liberdade pura e simples como um fim. É o da liberdade de exercício das mais legitimas autoridades: a do pai, da família e a dos reitores dos colégios. (CORÇÃO, 1958d, p. 54)

Em carta enviada ao jornalista mas não publicada, Anísio Teixeira comentou, genericamente, aqueles artigos e expôs suas ideias acerca da educação religiosa, destacando a importância de uma escola pública imparcial para atender aos que têm e aos que não têm religião. Em defesa da escola imparcial, o educador baiano argumentou que, assim como Corção, ele defendia a liberdade de ensino, considerando que a educação privada e a pública não deveriam estar sujeitas ao Estado, mas sim à sociedade. Sugeriu que fossem criados conselhos de pais para dirigirem a escola pública e fez questionamentos ao jornalista católico que merecem destaque, como o seguinte:

Não seria possível aceitar a idéia dos pais organizados também dirigindo o ensino público? Essa idéia que é mais espantosa do que a sua ainda encontrou nenhum apoio católico. Será que os católicos não acham que vão ser a maioria nos conselhos? Ou na realidade não têm confiança nos pais, mas nos padres? Defenderá o Sr. realmente, 
como defendo a liberdade de ensino ou a sua transferência a outro senhor, à Igreja? Havendo os pais conquistado a liberdade de crença, não deveriam eles ter logicamente a liberdade de escolha? Essa liberdade só existirá com uma escola imparcial entre as religiões. Essa imparcialidade não é irreligião, mas simplesmente tolerância entre as religiões. (TEIXEIRA, 1958)

Lamentavelmente, não há registro de resposta de Gustavo Corção à carta de Anísio Teixeira.

Silenciosa por muito tempo, a Maçonaria, antiga combatente pela laicidade do Estado, retornou ao campo durante a tramitação do projeto de LDB. Com efeito, essa organização foi decisiva na orientação laica do Estado, particularmente do ensino público, na República nascente. Muito combatida durante o Estado Novo, ela demorou a manifestar-se sobre temas políticos e educacionais, voltando a fazê-lo em 1959, justamente no ponto de inflexão do processo de gestação parlamentar da lei.

A primeira manifestação maçônica que encontramos foi num artigo assinado por A. M. Grillo no Boletim do Grande Oriente do Brasil, em setembro de 1959. 0 autor apresentou toda uma concepção de diretrizes e bases da educação nacional, na qual estava explícito o papel insubstituível do Estado na oferta de educação, sem impedir a iniciativa privada, que, ao contrário, deveria ser estimulada. Mas o ensino primário, ginasial, secundário, comercial e técnico deveria ser de inteira responsabilidade do Estado. Em termos doutrinários, a educação deveria promover a compreensão, a tolerância e a amizade entre todas as nações e grupos sociais e religiosos. Sintomaticamente, o esboço curricular do ensino primário e médio não previa o ensino religioso. No lugar dele, o ensino primário teria aulas de moral e cívica; o médio, de filosofia.

Sete meses depois, em maio de 1960, quando o projeto de LDB já havia sido aprovado pela Câmara dos Deputados e encontrava-se em tramitação no Senado, o Poder Central do
Grande Oriente do Brasil publicou no Boletim a circular 14/60, assinada pelo Grão-Mestre Ciro Werneck de Souza e Silva, destinada "a todos os maçons, lojas e corpos de nossa obediência”. 0 conteúdo da circular era a moralização da política, para o que sugeria numerosos procedimentos, como a adoção da cédula única na votação para os cargos eletivos.

No que diz respeito ao tema deste artigo, a circular do Grão-Mestre condenou o projeto de LDB e apresentou elementos inéditos naquela conjuntura, particularmente a defesa da laicidade do Estado e da educação, como se depreende do seguinte extrato:

Pelo restabelecimento dos princípios da Constituição de 1891, sobre a completa laicidade do ensino, sobre a secularização dos cemitérios, sobre a intransigente separação entre Igreja e Estado, princípio que está também escrito na atual Constituição Brasileira, mas que vem sendo todos os dias violado e desrespeitado, quer disfarçadamente quer abertamente, pelo clero e por alguns políticos;

Pela inclusão de nossa legislação do divórcio a vínculo e de dispositivos que defendam a supremacia do casamento civil sobre o religioso;

Sobre a necessidade de maior difusão da instrução em todos os graus, como único meio de podermos sustentar o regime democrático e as conquistas liberais dos nossos maiores, envidando todos os esforços para se garantir a laicidade e gratuidade do ensino primário, secundário, profissional, que deverá ser público e acessível a todos. (CIRCULAR, 1960, p. 103)

Temas caros à Maçonaria, como a separação entre Igreja e Estado, a secularização dos cemitérios, a prevalência do casamento civil sobre o religioso, a possibilidade do divórcio e a laicidade do ensino público, foram, então, divulgados a todos os maçons, com uma defesa da prevalência estatal na educação que não encontrou paralelo naquela conjuntura. 
A Associação dos Antigos Alunos da Faculdade de Filosofia, Ciências e Letras da Universidade de São Paulo voltou a expressar-se, lançando um manifesto publicado em $O$ Estado de São Paulo em 11 de fevereiro de 1960. Ele foi elaborado por comissão que teve como relator Florestan Fernandes, na época professor da Cátedra de Sociologia I daquela faculdade, cujo titular era Fernando de Azevedo. Repudiando com veemência o projeto aprovado pela Câmara dos Deputados e confiando que o Senado poderia "reparar os males produzidos pela infeliz orientação" até então seguida, o manifesto dizia que o texto não conseguia definir, entre outras coisas, "a importância da escola pública como fator de laicização do ensino e da formação da mentalidade científica”. Depois de destacar os pontos que mais ostensivamente expressavam os interesses das escolas privadas, confessionais e não confessionais, o manifesto concluiu ser a própria democracia que estava em risco.

Ainda em 1960, a I Convenção Espírita em Defesa da Escola Pública aprovou, em 16 de julho, uma declaração denominada Os espiritas e a escola pública, que foi publicada pela Revista Brasileira de Estudos Pedagógicos, do INEP. A primeira parte do documento, denominada plano geral, continha seis itens, que vão listados a seguir:

I - Ensino livre, gratuito e educação leiga para toda a população, através da escola pública, mantida pelo Estado, segundo a política educacional e a filosofia democrática da educação consagrada pela Constituição Federal; II - Liberdade para a iniciativa particular no ensino supletivo, em todos os graus, desde que respeitados os princípios democráticos e o caráter leigo do ensino público, indispensável à formação da nação, em bases humanistas.

III - Exclusão urgente do ensino religioso facultativo nas escolas públicas e particulares, por constituir fonte de discriminações e injustiças, prejudicando os superiores objetivos pedagógicos.
IV - Formação moral do ensino leigo como supletivo da família através de normas éticas de ordem geral e de educação cívica elevada, com vistas à formação humanista. V - Ensino de religião como matéria filosófica, nos cursos médio e superior, sem qualquer tendência sectária ou particularista.

VI - Instituição de penalidades legais para a prática de qualquer forma de discriminação nas escolas públicas e particulares, inclusive as decorrentes da posição civil dos pais. (OS ESPÍRITAS, 1960, p. 162-163)

Era uma plataforma sem dúvida radical, que combinava a defesa do ensino laico (dito leigo) nas escolas públicas e nas privadas. 0 item VI contém um elemento importante naquela época, que era a defesa de penalidades para a discriminação dos alunos devido à posição civil de seus genitores, com endereço certo: o das escolas católicas, que desligavam aqueles que tinham pais desquitados.

No plano doutrinário, o documento tratava da multiplicação de centros de difusão da doutrina espírita, bem como da manutenção das escolas espíritas existentes e da criação de outras. Nessas escolas, os pais poderiam proteger os filhos

das influências e da coação religiosa imperantes na maioria das escolas e até mesmo na escola pública atual, minada pela excrescência legal do ensino religioso facultativo. (OS ESPÍRITAS, 1960, p. 163)

Os protestantes, que foram ativos defensores da laicidade durante a elaboração das Constituições de 1934 e 1946, permaneceram silenciosos durante a tramitação da LDB. Talvez o realismo político explique esse silêncio, já que a Constituição determinava a oferta do ensino religioso nas escolas públicas.

Tudo somado, os laicos chegaram tarde e foram ineficazes - nada houve de parecido com a frente que se formou durante a Assembleia Constituinte de 1933/34. Eficazes 
foram a repressão do Estado Novo à Maçonaria, a entente Estado Novo-Igreja Católica, em 1935/37, e a ação de intelectuais católicos leigos, civis e militares na produção de uma nova hegemonia católica, que mostrou sua força no período de tramitação da LDB, até mesmo e principalmente nos anos seguintes, contribuindo fortemente para o sucesso do golpe civil-militar de 1964.

\section{Ensino religioso na LDB}

0 artigo sobre o ensino religioso nas escolas públicas no projeto de LDB encaminhado ao Congresso pelo Ministério da Educação foi calcado no artigo 168 da Constituição, ao qual foi acrescentado um parágrafo. Este determinava que o registro dos professores de ensino religioso seria realizado perante a respectiva autoridade religiosa. Tal artigo foi posto nas Disposições Gerais e Transitórias do projeto de LDB, espaço dotado de pequeno valor simbólico e de menor visibilidade, mas que oferecia eficácia legal como qualquer outro. Esse lugar foi mantido em toda a tramitação, permanecendo na lei promulgada.

A pretensão de controle do magistério da disciplina pela Igreja Católica foi correspondida pela $\mathrm{ABE}$, que, no esboço de LDB elaborado por ocasião da X Conferência Nacional de Educação (1950), propôs o seguinte:

Ministrarão o ensino religioso em estabelecimentos oficiais pessoas autorizadas pelos representantes autorizados das respectivas confissões religiosas. (artigo $7^{\circ}$ das Disposições Transitórias)

Um único parágrafo especificou que essas pessoas poderiam ser docentes:

A indicação poderá recair em professores públicos, desde que aceitem o encargo e a aprove a administração de que o estabelecimento de ensino for dependente. ${ }^{5}$

5 - Diário do Congresso Nacional, 12 fev. 1957, p. 20.
Cumpre registrar que o texto da entidade admitia, implicitamente, o uso de recursos públicos no ensino religioso, pois o tempo dos professores do magistério oficial era remunerado. A proposta da $\mathrm{ABE}$ foi encaminhada à Câmara dos Deputados, que a anexou ao projeto em tramitação $0^{6}$.

Em 8 de dezembro de 1956, o deputado evangélico Antunes de Oliveira (PTB-AM) ${ }^{7}$ apresentou substitutivo à Comissão de Educação e Cultura da Câmara, que aumentaria a competência das autoridades religiosas. Além do registro dos professores, a elas caberia a elaboração dos programas cujos temas deveriam ser ministrados, sem ataques a outros credos. Nota-se uma antiga precaução evangélica contra sua discriminação pelo clero e pelos adeptos da religião majoritária.

A despeito de visar ao reforço do poder das instituições religiosas, a exposição de motivos do deputado amazonense continha um parágrafo que apontava para o caráter efetivamente facultativo dessa disciplina, pois oferecia alternativas não confessionais à escola e ao aluno:

É lícito aos estabelecimentos que preferirem, ouvidos igualmente os alunos ou seus responsáveis, optar pelo estudo imparcial da história das religiões e noções de religiões comparadas, particularmente sob o aspecto ético. ${ }^{8}$

Essa proposta era de grande alcance na época e mantém-se atual, pois corresponde às orientações adotadas pelos currículos das escolas públicas de países da Europa que, diante da secularização da cultura, propiciam aos alunos uma alternativa ao ensino religioso, isto é, a possibilidade de passar do proselitismo, mesmo que dissimulado, para o conhecimento do fenômeno religioso em suas múltiplas manifestações. É interessante mencionar também que proposta desse tipo não foi apresentada na

6 - Diário do Congresso Nacional, 12 maio 1955, p. 2.334-2.336.

7- Albérico Antunes de Oliveira era pastor batista e ligado a atividades educacionais, tanto como professor do Colégio Estadual do Amazonas quanto como dirigente da Campanha Nacional dos Educandários Gratuitos. 8 - Diário do Congresso Nacional, 8 dez. 1956, p. 1.235-1.236. 
Constituinte de 1946, quando a discussão sobre essa disciplina foi muito mais ampla e livre do que na tramitação da LDB.

Todavia, na reconstituição do projeto de LDB, em 1957, a Subcomissão Relatora preferiu ignorar ambas as sugestões de Antunes de Oliveira. Nova subcomissão, formada pelos deputados Lauro Cruz (UDN-SP), Nestor Jost (PSD-RS) e Alfredo Palermo (PDC-SP), apresentou substitutivo ao projeto de LDB, publicado no DCN em 28 de maio de 1958, que incluiu um parágrafo no artigo sobre o ensino religioso determinando que as classes dessa disciplina não dependeriam do número de alunos ${ }^{9}$. Esse dispositivo só adquire sentido diante dos temores dos efeitos inerciais do decreto 19.941, de 30 de abril de 1931, que fixava em vinte o número mínimo de alunos para que uma classe de ensino religioso fosse instalada. As diversas versões posteriores do projeto oscilaram na inclusão e na retirada desse parágrafo com a referência negativa ao número de alunos, que acabou figurando na versão finalmente aprovada pela Câmara, a qual foi mantida pelo Senado.

Houve, assim, mudanças de opinião sobre a organização dos sistemas educacionais e os subsídios públicos ao setor privado, mas elas se deram à margem dos conflitos principais que cindiam o Congresso. Os projetos substitutivos apresentados pelo deputado Carlos Lacerda provocaram turbulências na tramitação da LDB, mas não no tocante ao ensino religioso nas escolas públicas, tema, aliás, que nenhum dos projetos sequer mencionou ${ }^{10}$. Isso é surpreendente, pois sua assessoria era toda formada de notórios quadros católicos, como a professora Sandra Cavalcanti ${ }^{11}$. Teria sido essa omissão um aceno à composição política?

9- Lauro Cruz e Alfredo Palermo tinham conhecidas vinculações políticas e profissionais com a Igreja Católica.

10- 0 primeiro substitutivo foi apresentado por esse deputado em 29 de novembro de 1958 e o segundo, em 15 de janeiro de 1959.

11- Militante da Ação Católica, Sandra Cavalcanti era professora do Instituto de Educação do Distrito Federal. Quando Lacerda apresentou seus projetos substitutivos, ela era vereadora no DF. Em 1960, foi eleita deputada no recém-criado Estado da Guanabara, do qual Lacerda foi 0 primeiro governador.
Não sabemos se tal intenção existiu, mas, no fim desse ano, uma emenda tão surpreendente quanto aquela omissão foi apresentada, vedando o emprego de recursos financeiros governamentais no ensino religioso nas escolas públicas. Trata-se de emenda apresentada pelo deputado Aurélio Vianna (PSB-AL) ${ }^{12}$, que inseriu uma condição na forma de oração intercalada no caput do artigo correspondente - sem ônus para os poderes públicos -, que foi aprovada pela Comissão de Educação e Cultura, em 25 de novembro de $1959^{13}$.

Estavam presentes treze deputados na reunião que aprovou a emenda: Coelho de Souza (PL-RS), presidente, Fernando Sant'Ana (PTBBA), Paulo Freire (PSP-MG), Lauro Cruz (UDNSP), Aderbal Jurema (PSD-PE), Derville Allegretti (PR-SP), Cardoso de Menezes (UDN-DF), Plínio Salgado (PRP-PR), Santiago Dantas (PTB-DF), Celso Brant (PR-MG), Dirceu Cardoso (PSDES), Aurélio Vianna (PSB-AL) e Lenoir Vargas (PSD-SC). Ausentes sete deputados: Tristão da Cunha (PR-MG), Antonio Dino (PSD-MA), Carlos Lacerda (UDN-DF), José Lopes (PTB-PE), José Silveira (PTB-PR), Manoel de Almeida (PSD-MG) e Yukishiguo Tamura (PSD-SP).

Apesar de ter sido tema longamente debatido na Assembleia Nacional Constituinte de 1946, sendo derrotada toda e qualquer tentativa de restrição de uso dos sistemas públicos de ensino para difusão religiosa, inclusive o uso nele de recursos financeiros, a Câmara aprovou sem alarde o dispositivo limitador do deputado Aurélio Vianna. As sucessivas versões do projeto mantiveram essa emenda no artigo sobre o ensino religioso, que passou a ter a seguinte redação:

Art. 97 - 0 ensino religioso constitui disciplina dos horários das escolas oficiais, é de matrícula facultativa, e será ministrada

12 - Aurélio Vianna da Cunha Lima começou sua carreira política na Esquerda Democrática, partido do qual foi dirigente em Alagoas. Com a formação do PSB, em agosto de 1947, ele se transferiu para este, pelo qual se elegeu deputado constituinte estadual.

13- 0 Diário do Congresso Nacional de 15 de dezembro de 1959 transcreveu ata da $18^{a}$ reunião ordinária da Comissão de Educação e Cultura da Câmara dos Deputados, realizada no dia 25 de novembro de 1959. 
sem ônus para os Poderes Públicos, de acordo com a confissão religiosa do aluno, manifestada por ele, se for capaz, ou por seu representante legal ou responsável.

Parágrafo $1^{\circ}$. - A formação de classe para o ensino religioso independe de número mínimo de alunos.

Parágrafo $2^{\circ}$. - 0 registro de professores de ensino religioso será realizado perante a autoridade religiosa respectiva. (BRASIL, 1961, grifos nossos)

Essa redação permaneceu na versão aprovada pelo plenário da Câmara e foi aceita pelo Senado, conservando-se íntegra no texto da lei promulgada pelo presidente João Goulart.

A versão final do artigo sobre o ensino religioso, aprovada sem nenhuma reação aparente, pode ter sido resultado de um acordo entre os membros da Comissão da Educação e Cultura a fim de contemplar diferentes vertentes ideológicas. Essa possibilidade decorre da fala de quatro dos quinze deputados presentes na $16^{\text {a }}$ reunião extraordinária da Comissão. Vejamos as passagens mais sugestivas.

0 deputado San Tiago Dantas (PTB-MG) congratulou-se com seus colegas por terem produzido "um projeto de lei equilibrado, que representa a opinião média do país”, no qual "não se infiltrou uma palavra de demagogia". Aderbal Jurema (revisor geral do projeto) destacou a atuação de Carlos Lacerda, San Tiago Dantas, Aurélio Vianna e Lauro Cruz, este relator geral. Frisou que a Comissão muito devia ao seu presidente, Coelho de Souza (PL-RS),

pela maneira equilibrada e correta com que se houve na direção dos trabalhos e a habilidade que demonstrou nas fases mais agudas, não permitindo que a Comissão se desagregasse em torno das divergências por vezes aprofundadas.

Na fala de Coelho e Souza, a dimensão política e democrática foi enfatizada:
Esforçamo-nos para produzir uma obra que a todos agrade, mas não pretendemos seja aceita sem restrições pelos técnicos, burocratas nem que os sectários nela não encontrem falhas. 0 grande mérito da Comissão, neste trabalho, foi, sem dúvida, a conciliação das várias tendências com que nos defrontamos. Vale aqui salientar a atividade desenvolvida patrioticamente, não só pelo senhor revisor geral, deputado Aderbal Jurema, como também, pelo deputado Aurélio Vianna, que apresentou no seio desta Comissão as emendas conciliatórias que possibilitaram a conclusão de nosso trabalho. A lição colhida das lutas que tivemos todos, evidencia que leis dessa responsabilidade podem perfeitamente ser elaboradas nos regimes democráticos. ${ }^{14}$

Aprovado o projeto de lei pela Comissão de Educação e Cultura, o plenário manifestou-se em diferentes direções, mas a inserção restritiva de Aurélio Vianna prosseguiu. 0 Senado também a aprovou.

Em suma, o artigo 97 da LDB foi produto, então, de: (i) transcrição do dispositivo constitucional sobre o ensino religioso; (ii) ampliação dos interesses das instituições religiosas, especialmente da Igreja Católica, pelo parágrafo adicionado pelo projeto de 1948, tratando do efetivo das salas de aula e do registro de professores, acrescentado pela Câmara dos Deputados; e (iii) limitação desses interesses na cláusula restritiva ao uso dos recursos públicos para o ensino religioso nas escolas públicas, inserida por proposta de deputado da esquerda e aceita pela direita.

\section{À guisa de conclusão}

Para quem esperava encontrar candentes conflitos parlamentares em torno da questão do ensino religioso nas escolas públicas no processo de produção da LDB, o exame da bibliografia e

14 - Diário do Congresso Nacional, 19 dez. 1959, p. 9.769. 
do Diário do Congresso Nacional revelou-se uma decepção. Nos treze anos de tramitação do projeto de lei, as disputas concentraram-se em outras questões, principalmente na centralização dos sistemas de ensino, na transferência de recursos financeiros públicos para o setor privado e na composição dos conselhos de educação. Nem mesmo o deputado Carlos Lacerda, autor de dois extremados projetos privatistas, incendiou essa questão, pois seus projetos de lei sequer mencionavam o ensino religioso nas escolas públicas.

Não bastasse a surpresa diante da ausência de questionamento do ensino religioso nos debates parlamentares, outra veio reforçá-la: a silenciosa aprovação de emenda que proibia o emprego de recursos públicos nessa disciplina. Tal restrição foi incluída numa das versões do projeto de LDB por deputado do Partido Socialista Brasileiro, sem que houvesse reações ou ponderações. A hipótese de um equívoco momentâneo não procede, pois tal emenda, aprovada na Comissão de Educação e Cultura da Câmara, não foi suprimida no plenário. 0 Senado, apesar das inúmeras alterações promovidas no projeto, deixou incólume essa restrição, a qual, de modo algum, poderia passar despercebida nas duas casas do Congresso Nacional.

Ou seja, o que a Constituinte de 1946 recusou, o Congresso aceitou sem manifestação contrária alguma, década e meia depois. Como entender isso, se a Igreja Católica tinha, há muito, questão fechada sobre esse ponto, tendo lutado por ele em outras ocasiões e saído vencedora nas Constituintes de 1934, de 1946 e depois? Senão, vejamos: após o golpe militar, o apoio oferecido pelo clero e pelas massas católicas foi recompensado de diversas maneiras, entre elas, a supressão, pela Lei ${ }^{\circ}$ 5.692/71, da cláusula restritiva da Lei $\mathrm{n}^{0} 4.024 / 61$ ao uso de recursos públicos no ensino religioso; e de novo, a supressão do texto da segunda LDB de restrição semelhante, pela Lei $\mathrm{n}^{\circ}$ 9.475/97, aprovada em regime de urgência, às vésperas da visita do papa João Paulo II ao Brasil.

Não há como supor, portanto, que se tratasse de matéria secundária ou sem importância. Tratava-se, como sugerem as falas dos deputados na última reunião da Comissão de Educação e Cultura, de um acordo político entre seus membros com o propósito de atender a diferentes interesses em conflito em torno de: centralização versus descentralização; ensino público versus ensino privado; confessionalismo versus laicidade.

A cláusula restritiva do artigo 97 seria a compensação pelo apoio a pontos da plataforma da liberdade de ensino dado por um setor da esquerda parlamentar, representada, na Comissão de Educação e Cultura da Câmara, pelos deputados Aurélio Vianna e Santiago Dantas. Para essa hipotética solução de compromisso, a omissão de Carlos Lacerda constituiu condição de possibilidade e poderia até mesmo ter sido um aceno. Ou seja, diante da prioridade da presença obrigatória de representantes da iniciativa privada nos órgãos colegiados de deliberação dos sistemas de ensino e da garantia de subsídios governamentais, entre outros, concedeu-se a restrição no uso de recursos públicos para o ensino religioso.

Se esse acordo de fato existiu, pode não ter sido o único entre os contendores. Anísio Teixeira publicou artigo quatro meses após a promulgação da lei, no qual, no calor da hora, fez um balanço do produto. Ele afirmou que a LDB recém-promulgada pelo presidente Goulart não era a lei que o Brasil precisava para enfrentar os desafios da mudança; todavia, ela teria representado "meia vitória, mas vitória” (TEIXEIRA, 1962). Se a lei não propiciava a formação de um sistema de ensino público à altura das circunstâncias do país, a caminho de se transformar na grande nação ainda desejada, ela propiciaria a autonomia dos sistemas estaduais de educação, abrindo caminho para o desenvolvimento educacional na direção devida.

Será que, para os privatistas, representados particularmente pela Igreja Católica, a LDB também significou meia vitória, mas vitória? Levando-se em conta as análises realizadas por Luiz Antônio Cunha (1991, 2007), a resposta é 
negativa: para os privatistas, a LDB propiciou vitória plena. Esse resultado teria sido efeito combinado dos dispositivos da lei e do contexto em que ela foi implementada, já que os grupos políticos que deram sustentação à sua versão privatista foram os mesmos que apoiaram o golpe militar, dois anos depois de sua promulgação. Vitoriosos, eles vieram a ocupar por duas décadas os postos de direção política e ideológica do campo educacional.

\section{Referências}

BARROS, Roque Spencer Maciel de (Org.). Diretrizes e Bases da Educação Nacional. São Paulo: Pioneira, 1960.

BRASIL. Presidência da República. Constituição dos Estados Unidos do Brasil. Rio de Janeiro, 18 set. 1946.

Lei no 4.024, de 20 de dezembro de 1961 Fixa as Diretrizes e Bases da Educação Nacional. Diário Oficial da União, Brasilia, DF, 27 dez. 1961.

BUFFA, Ester. Ideologias em conflito: escola pública e escola privada. São Paulo: Cortez \& Moraes, 1979.

CIRCULAR 14/60 - Diretrizes e Bases do Ensino. Boletim do Grande Oriente do Brasil, Rio de Janeiro, ano 86, n. 5, mai. 1960. CONTRA o ensino religioso oficial os antigos alunos da Faculdade de Filosofia... 0 Estado de São Paulo, 13 jan. 1957.

CORÇÃo, Gustavo. A liberdade de ensino. 0 Estado de São Paulo, 19 jan. 1958a.

A quem compete educar? 0 Estado de São Paulo, 25 jan.1958b.

Uma afronta pessoal. 0 Estado de São Paulo, 02 fev.1958c.

Ainda a liberdade de ensino. 0 Estado de São Paulo, 16 fev. 1958d.

CRUZ, Mariano da. Vinte anos a serviço da educação. Rio de Janeiro: AEC, 1966.

CUNHA, Luiz Antônio. A organização do campo educacional: as conferências de educação. Educação \& Sociedade, Campinas, n. 9, p. 5-48, mai. 1981.

Educação, Estado e democracia no Brasil. São Paulo: Cortez, 1991.

Sintonia oscilante: religião, moral e civismo no Brasil - 1931/1997. Cadernos de Pesquisa, São Paulo, v. 37, n. 131, p. 285-302, maio/ago. 2007.

FERNANDES, Florestan. Educação e sociedade no Brasil. São Paulo: Dominus/EDUSP, 1966.

LIMA, Alceu Amoroso. 0 Estado e a educação. Síntese, Rio de Janeiro, n. 1, 1959.

LIMA, Danilo. Educação, igreja e ideologia. Rio de Janeiro: Francisco Alves, 1978.

MAIS uma vez convocados - Manifesto dos Educadores. Revista Brasileira de Estudos Pedagógicos, Rio de Janeiro, v. XXXI, n. 73, jan./mar. 1959.

MONTALVÃO, Sérgio de Sousa. A LDB de 1961: conceitos, representações e confrontos no campo político-pedagógico. Tese (Doutorado) - Fundação Getúlio Vargas, Rio de Janeiro, 2011. 
MOREIRA, João Roberto. Educação e desenvolvimento no Brasil. Rio de Janeiro: Centro Latino-Americano de Pesquisa em Ciências Sociais, 1960.

OLIVEIRA, Romualdo Portela de. Educação e sociedade na Assembléia Constituinte de 1946. Dissertação (Mestrado) Faculdade de Educação, Universidade de São Paulo, 1990.

OS ESPÍRITAS e a escola pública. Revista Brasileira de Estudos Pedagógicos, Rio de Janeiro, v. XXXIV, n. 79, jul./set. 1960.

ROMANELLI, Otaiza de Oliveira. História da Educação no Brasil (1930/1973). Petrópolis: Vozes, 1978.

SANFELICE, José Luiz. 0 Manifesto dos Educadores (1959) à luz da história. Educação e Sociedade, Campinas, v. 28, n. 99, p. 542-557, ago. 2007.

SAVIANI, Dermeval. Educação brasileira: estrutura e sistema. Campinas: Autores Associados, 2005.

. História das idéias pedagógicas no Brasil. Campinas: Autores Associados, 2007.

SOUZA, Luiz Alberto Gómez de (Org.). Cristianismo hoje. Rio de Janeiro: Editora Universitária/UNE, 1962.

TEIXEIRA, Anísio. Carta de Anísio Teixeira para Gustavo Corção. Arquivo Anísio Teixeira, CPDOC/FGV (AT C 1958.02.23). 23 fev. 1958. Disponível em: <http://www.bvanisioteixeira.ufba.br/cartas/corcao.htm>. Acesso em: 10 mai. 2011.

. Meia vitória, mas vitória. Revista Brasileira de Estudos Pedagógicos, Rio de Janeiro, v. XXXVII, n. 86, abr./ jun. 1962.

VILLALOBOS, João Eduardo Rodrigues. Diretrizes e bases da educação: ensino e liberdade. São Paulo: Pioneira/EDUSP, 1969.

Recebido em: 24.11.2011

Aprovado em: 01.03.2012

Luiz Antônio Cunha é professor titular da Faculdade de Educação da Universidade Federal do Rio de Janeiro.

Vânia Fernandes é doutoranda em Educação pela Universidade Federal do Rio de Janeiro e professora da rede estadual de educação do Rio de Janeiro. E-mail: vania_fernanv@yahoo.com.br. 